\title{
Cryogenic electron beam induced chemical etching
}

\author{
Aiden A. Martin, Milos Toth* \\ School of Physics and Advanced Materials, University of Technology, Sydney, P.O. Box \\ 123, Broadway, New South Wales 2007, Australia \\ E-mail: Milos.Toth@uts.edu.au
}

\begin{abstract}
Cryogenic cooling is used to enable efficient, gas mediated electron beam induced etching (EBIE) in cases where the etch rate is negligible at room and elevated substrate temperatures. The process is demonstrated using nitrogen trifluoride $\left(\mathrm{NF}_{3}\right)$ as the etch precursor, and $\mathrm{Si}, \mathrm{SiO}_{2}, \mathrm{SiC}$ and $\mathrm{Si}_{3} \mathrm{~N}_{4}$ as the materials volatilized by an electron beam. Cryogenic cooling broadens the range of precursors that can be used for EBIE, and enables high resolution, deterministic etching of materials which are volatilized spontaneously by conventional etch precursors as demonstrated here by $\mathrm{NF}_{3}$ and $\mathrm{XeF}_{2}$ EBIE of silicon.
\end{abstract}

KEYWORDS: electron beam induced etching, nanofabrication, silicon, nitrogen trifluoride, reaction kinetics, surface chemistry

Gas mediated electron beam induced etching (EBIE) enables maskless, beam-directed editing of materials at the nanoscale. Etching has been demonstrated using precursors such as $\mathrm{H}_{2} \mathrm{O}, \mathrm{O}_{2}, \mathrm{H}_{2}, \mathrm{Cl}_{2}, \mathrm{SF}_{6}, \mathrm{XeF}_{2}$ and $\mathrm{ClF}_{3} \cdot{ }^{1-4}$ However, the range of precursor-substrate combinations that is appropriate for EBIE has, to date, been small compared to conventional

\footnotetext{
${ }^{*}$ To whom correspondence should be addressed
} 
plasma etching ${ }^{5,6}$ because many of the precursors that yield radicals responsible for plasma etching have properties that are undesirable for EBIE. Ideally, a substrate etched by EBIE is exposed to a vapor-phase precursor that adsorbs to, but does not etch the material spontaneously. An electron beam is then used to dissociate surface-adsorbed precursor molecules, generating fragments that react with the substrate to produce species which desorb, thereby volatilizing substrate regions near the beam $^{1}$ (see inset of Figure 1(a)). EBIE is typically performed at room temperature because both heating and cooling can inhibit etching by increasing and decreasing the thermal desorption rate of surface-adsorbed precursor molecules and the final reaction products, respectively.

The limited scope of room temperature EBIE is exemplified by nitrogen trifluoride $\left(\mathrm{NF}_{3}\right)$, a common fluorine precursor used in laser ${ }^{7}$ and plasma ${ }^{8}$ induced etching of $\mathrm{Si}$ and $\mathrm{SiC} .{ }^{9} \mathrm{NF}_{3}$ satisfies most key requirements for EBIE: it has a large electron dissociation cross-section; ${ }^{10}$ high vapour pressure; relatively low toxicity and broad material compatibility (in particular, $\mathrm{NF}_{3}$ does not cause corrosion of components in electron microscope chambers, and does not etch most solids spontaneously, including silicon $\left.{ }^{11}\right)$. Despite these favorable characteristics, $\mathrm{NF}_{3}$ mediated EBIE has previously not been demonstrated, likely due to poor surface coverage at room temperature. Weak physisorption has been observed on platinum, ${ }^{12}$ gold (desorption energy $=0.219 \mathrm{eV})^{13}$ and ruthenium. ${ }^{14}$ Standard theory of gas mediated electron beam processing ${ }^{1,2,15-22}$ predicts that the low $\mathrm{NF}_{3}$ adsorption energies (on the order of $200 \mathrm{meV}$ ) give rise to very low etch rates at and near room temperature (Supporting Information Section S3). Coverage can, in principle, be increased by substrate cooling since the desorption rate decreases exponentially with reciprocal temperature (Supporting Information S3). Cooling does, however, also inhibit thermal desorption of the final reaction products, and has therefore not been used to enhance EBIE.

Here we show that cryogenic substrate cooling can enable efficient EBIE in cases where the room temperature etch rate is negligible. We demonstrate efficient EBIE of materials that contain Si, C, N and $\mathrm{O}$ at temperatures as low as $100 \mathrm{~K}$. The results show that a range 
of EBIE reaction products can desorb (during electron irradiation) at cryogenic substrate temperatures, and that cryogenic substrate cooling broadens the range of precursors that can be used to realize EBIE. $\mathrm{NF}_{3}$ EBIE of $\mathrm{Si}$ is particularly significant because silicon is most often etched using $\mathrm{XeF}_{2}$ which gives rise to spontaneous etching and roughening of Si, while the electron beam merely accelerates the local etch rate. ${ }^{23}$ The only alternatives for EBIE of Si reported to date are $\mathrm{SF}_{6},{ }^{24}$ which is highly inefficient, and $\mathrm{Cl}_{2}{ }^{25,26}$ which is highly corrosive, toxic and flammable. Cryogenic, $\mathrm{NF}_{3}$ EBIE overcomes these problems, and enables deterministic, high resolution editing of Si and associated devices.

EBIE was carried out using an FEI Nova NanoSEM variable pressure ${ }^{27,28}$ scanning electron microscope (SEM) equipped with a magnetic immersion lens gaseous secondary electron detector $^{29}$ and a liquid nitrogen cooling stage. Substrates used for EBIE were $\mathrm{Si}, \mathrm{SiO}_{2}, \mathrm{SiC}$ and $\mathrm{Si}_{3} \mathrm{~N}_{4}$. Cylindrical etch pits were fabricated under $8.4 \mathrm{~Pa}\left(8.4 \times 10^{-2} \mathrm{mBar}\right)$ of $\mathrm{NF}_{3}$ a using a stationary, $10 \mathrm{keV}, 3.4 \mathrm{nA}$ electron beam that was under-focused to generate a top-hat flux profile (see Supporting Information Sections S1a and b for additional details). This configuration, shown schematically in the inset of Fig. 1, yields conditions that are optimal for quantitative analysis of EBIE rates. ${ }^{3,20,22,30}$ The temperature was always above the condensation point of the precursor gas (Supporting Information Section S1c), in contrast to ice lithography and cryogenic electron beam induced deposition. ${ }^{31-34}$

Comparisons to $\mathrm{Cl}_{2}$ mediated EBIE of Si (Figure 3a) were performed using the electron exposure conditions used by Roediger et. al., ${ }^{25,26}$ an $\mathrm{NF}_{3}$ pressure of $6.5 \mathrm{~Pa}$ and a substrate temperature of $106 \mathrm{~K}$. Delocalized etching of $\mathrm{Si}$ caused by $\mathrm{XeF}_{2}$ precursor vapor (Sigma Aldrich, $99.99 \%$ ) was demonstrated (Figure 3b) using a gas injection capillary located $\sim 100 \mu \mathrm{m}$ from the substrate surface in high vacuum $\left(\sim 3.8 \times 10^{-3} \mathrm{~Pa}\right)$, at room temperature (Supporting Information Section S1d). A framed 'NF3' symbol (Figure 4) was etched into Si by a $20 \mathrm{keV}, 9.9 \mathrm{nA}$ electron beam, using an $\mathrm{NF}_{3}$ pressure of $6.5 \mathrm{~Pa}$ and a substrate temperature of $106 \mathrm{~K}$. Total processing time was 5 min with an electron beam dwell time of $13 \mathrm{~ms}$ per pixel. 
Figures 1a and b show plots of the depth of pits made in Si (measured using an atomic force microscope (AFM), see Supporting Information Section S1f) by $\mathrm{NF}_{3}$ mediated EBIE as a function of temperature $(T)$. The etch rate is negligible at room temperature and increases as the substrate temperature is reduced to $\sim 98 \mathrm{~K}$. At any given temperature, the etch rate is constant with time (over the experimental time scale), as seen in Figure 2.

Figure $1 \mathrm{~b}$ shows that the etch rate scales exponentially with $\frac{1}{T}$ at reciprocal temperatures greater than $\sim 0.0075 \mathrm{~K}^{-1}$. At lower values of $\frac{1}{T}$ (i.e. higher temperatures), EBIE is inhibited through a thermally-activated mechanism that we ascribe tentatively to surface diffusion of residual contaminants (such as hydrocarbons and $\mathrm{H}_{2} \mathrm{O}$ ) ${ }^{35,36}$ present at the substrate surface. Residual contaminants compete for surface sites with $\mathrm{NF}_{3}$ adsorbates and can therefore inhibit EBIE, particularly at elevated temperatures where the $\mathrm{NF}_{3}$ coverage is low and diffusivity (of all species at the surface) is relatively high.

At reciprocal temperatures greater than $\sim 0.0075 \mathrm{~K}^{-1}$, the exponential increase in etch
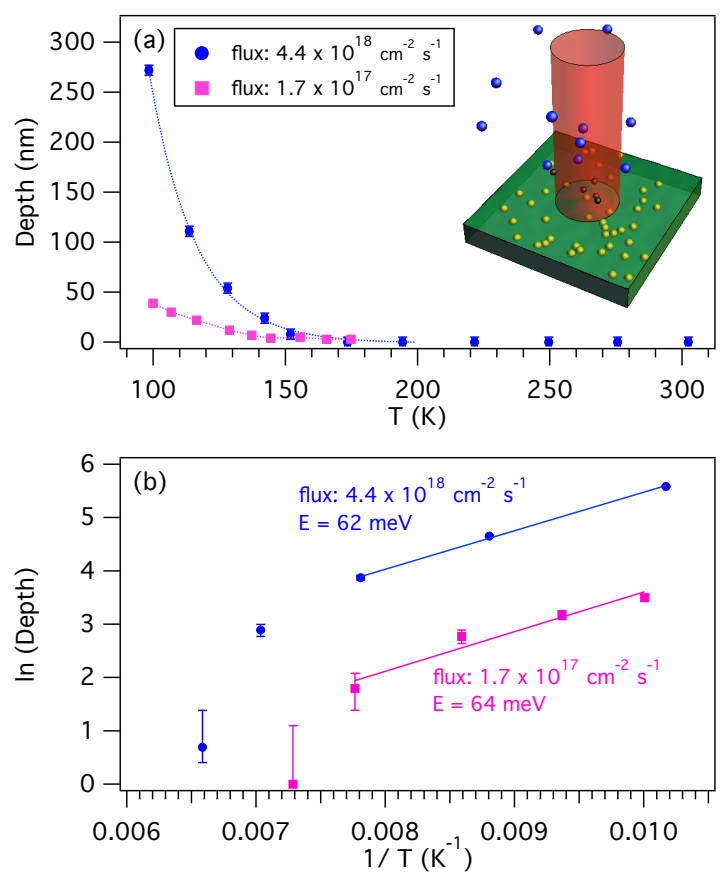

Figure 1: (a) Etch pit depth versus substrate temperature $(T)$ for $\mathrm{NF}_{3}$ mediated EBIE of Si. (b) Plots used to extract the activation energies $E$ by Arrhenius analyses of the data in (a). Inset: Schematic illustration of electron beam induced etching performed using a stationary beam defocused to attain a top-hat electron flux profile. 


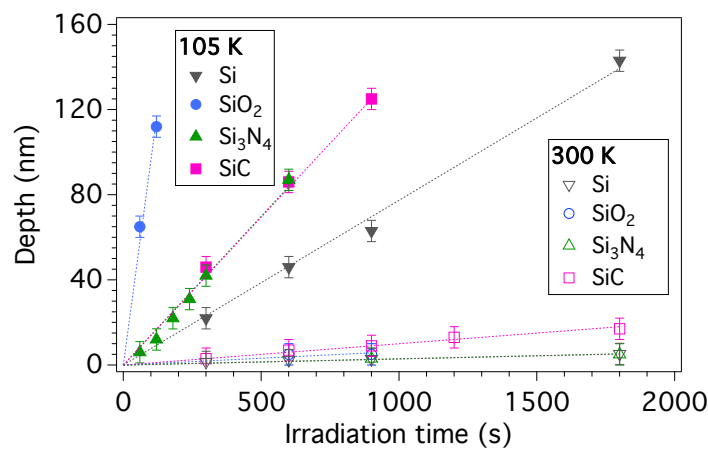

Figure 2: Etch pit depth versus time measured for $\mathrm{Si}, \mathrm{SiO}_{2}, \mathrm{SiC}$ and $\mathrm{Si}_{3} \mathrm{~N}_{4}$ etched by $\mathrm{NF}_{3}$ mediated EBIE at substrate temperatures of 105 and $300 \mathrm{~K}$.

rate with $\frac{1}{T}$ is attributed to a corresponding increase in the surface coverage of $\mathrm{NF}_{3}$ caused by a decrease in the $\mathrm{NF}_{3}$ residence time at the substrate surface (Supporting Information Section S3). We note that an exponential increase in EBIE rate with $\frac{1}{T}$ can not be explained by the temperature-dependence of the adsorbate diffusion coefficient which decreases with $\frac{1}{T}$ (Supporting Information Section S3).

In our experiments, analysis of the EBIE reaction products by mass spectrometry was not possible due to the high $\mathrm{NF}_{3}$ pressure and small quantity of volatile molecules generated in EBIE. However, based on other dry chemical etch processes, ${ }^{37}$ and $\mathrm{XeF}_{2}$ mediated EBIE of $\mathrm{Si}^{38}$ the etch reaction products are most likely of the form $\mathrm{SiF}_{n}$, where $n=1$ to 4 , and the thermal desorption rate increases as $\mathrm{n} \rightarrow 4 .^{39}$

The etch pit depth data shown in Figure $1 \mathrm{~b}$ can be used to extract the thermal activation energy $(E)$ of the process responsible for the observed temperature dependence. Arrhenius analyses of the curves yield an activation energy of $\sim 63 \pm 1 \mathrm{meV}$ for EBIE performed using electron fluxes of $1.7 \times 10^{17} \mathrm{~cm}^{-2} \mathrm{~s}^{-1}$ and $4.4 \times 10^{18} \mathrm{~cm}^{-2} \mathrm{~s}^{-1}$, respectively. This value of $E$ serves as a lower limit for the adsorption energy of $\mathrm{NF}_{3}$, as discussed in the Supporting Information (Sections S4 and S5).

$\mathrm{NF}_{3}$ mediated EBIE was also applied to silicon oxide, carbide and nitride to determine the etch efficiency of materials other than Si. The etch rates of all three compounds are very low at room temperature, and increase significantly at the cryogenic temperature of 

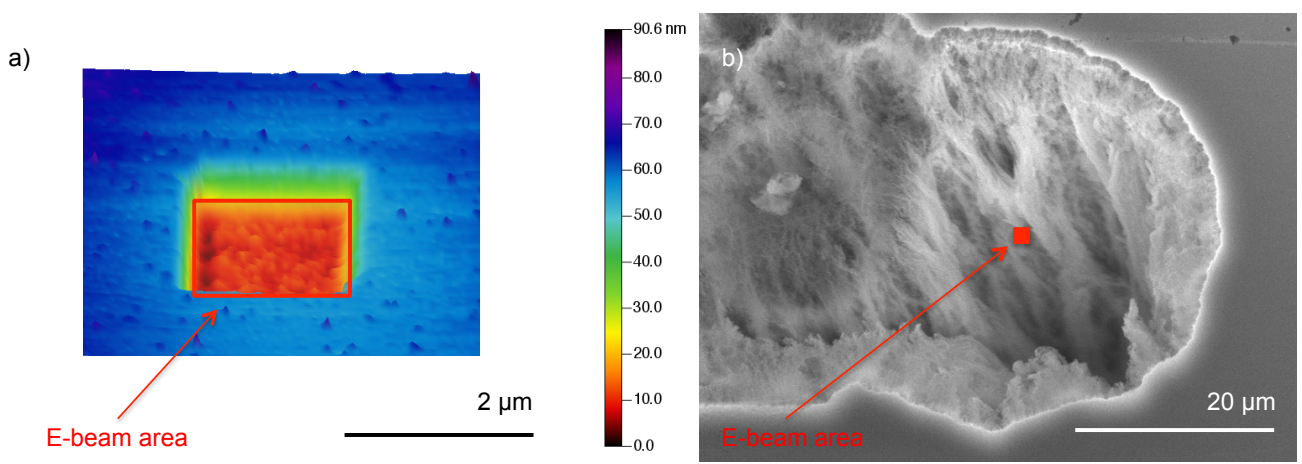

Figure 3: (a) AFM image of a rectangular pit made in Si by $\mathrm{NF}_{3}$ mediated EBIE, illustrating the absence of delocalized damage produced by spontaneous etching of Si. (b) SEM image of Si processed by $\mathrm{XeF}_{2}$ mediated EBIE using the same electron exposure parameters as those used in (a). Red rectangles show the areas that were scanned by the electron beam and correspond to the nominal areas of etch pits made by EBIE. The image in (b) shows delocalized damage caused by spontaneous etching of $\mathrm{Si}$ by $\mathrm{XeF}_{2}$ that occurred during EBIE.

$105 \mathrm{~K}$, as seen in Figure 2. The volumetric etch rates at cryogenic temperature are $9.1 \times 10^{4}$, $1.1 \times 10^{6}, 1.6 \times 10^{5}$ and $1.6 \times 10^{5} \mathrm{~nm}^{3} \mathrm{~s}^{-1}$ for $\mathrm{Si}, \mathrm{SiO}_{2}, \mathrm{Si}_{3} \mathrm{~N}_{4}$ and $\mathrm{SiC}$, respectively. $\mathrm{SiO}_{2}$ exhibited the highest volumetric etch rate, likely due to the existence of additional reaction pathways enabled by oxygen, such as the generation of $\mathrm{SiOF}_{2}{ }^{40}$ and $\mathrm{OF}$ species, ${ }^{41}$ and a lower concentration of silicon atoms in the material.

In the case of $\mathrm{SiO}_{2}$ and $\mathrm{Si}_{3} \mathrm{~N}_{4}$, the desorption of nitrogen and oxygen is not surprising at cryogenic temperatures. However, the carbon present in $\mathrm{SiC}$ needs to be volatilized by radicals produced by electron dissociation of $\mathrm{NF}_{3}$ adsorbates. The volatile reaction products are most likely of the form $\mathrm{CF}_{\mathrm{x}}$ (where $\mathrm{x}=1$ to 4 ).

Next, we compare the efficacy of the cryogenic $\mathrm{NF}_{3}$ etch process to room temperature alternatives reported to date in the EBIE literature. Electron exposure conditions used by Roediger et. al. for $\mathrm{Cl}_{2}$ mediated $\mathrm{EBIE}$ of $\mathrm{Si}^{25,26}$ were replicated using $\mathrm{XeF}_{2}$ and $\mathrm{NF}_{3}$. The use of $\mathrm{XeF}_{2}$ results in highly delocalized damage, caused by rapid spontaneous etching of Si. For example, Figure 3b shows a substrate region that contains an etch box with a nominal area of $1.5 \times 1.5 \mu \mathrm{m}$, and a region of severe damage produced by $\mathrm{XeF}_{2}$ that extends $\sim 20 \mu \mathrm{m}$ from the rectangle scanned by the beam. Such rapid, delocalized etching by $\mathrm{XeF}_{2}$ is typical when the native oxide layer is compromised (by pinhole defects, or by EBIE). This 
behavior is clearly unfavorable as it inhibits the ability to etch Si with high spatial resolution (Supporting Information Section $\mathrm{S} 1 \mathrm{e}$ ). In comparison, $\mathrm{NF}_{3}$ mediated EBIE did not give rise to any observable spontaneous etching of the Si substrate. Instead, it yielded a well defined etch pit with a depth of $\sim 55 \mathrm{~nm}$ (Figure 3a), and a volumetric etch rate that is $\sim 2.4$ times greater than that of $\mathrm{Cl}_{2}$ under the same electron exposure conditions.

A complex pattern etched into $\mathrm{Si}$ using $\mathrm{NF}_{3}$ is shown in Figure 4. It demonstrates high resolution, localized editing of $\mathrm{Si}$ in the absence of highly toxic, flammable and corrosive precursors that are unsuitable for use in electron microscopes (ultimate EBIE resolution is governed by the electron beam diameter, proximity effects and material roughening that occurs during etching). ${ }^{42}$ We note that $\mathrm{SF}_{6}$ has also been reported as a precursor for room temperature EBIE of Si. ${ }^{24}$ This etch process is, however, extremely inefficient and inappropriate for high resolution EBIE, and may give rise to unintended deposition of sulphur. ${ }^{43}$

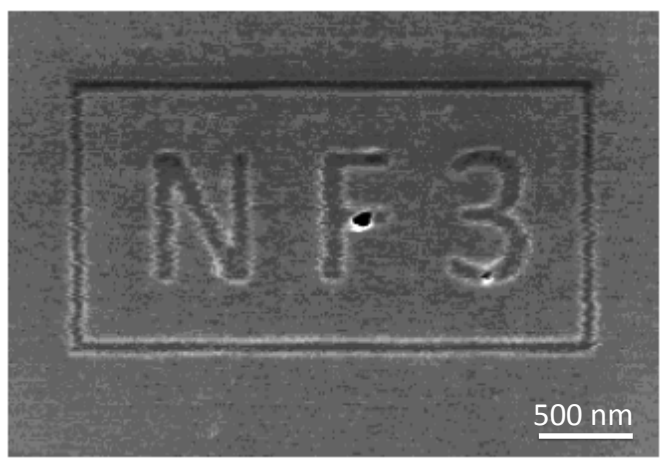

Figure 4: SEM image of a framed 'NF3' symbol etched into Si by $\mathrm{NF}_{3}$ mediated EBIE with a line resolution of $\sim 85 \mathrm{~nm}$.

In summary, cryogenic cooling was used to enable efficient gas mediated electron beam induced etching using nitrogen trifluoride as the etch precursor. The etch rate is limited by thermal desorption of weakly bound $\mathrm{NF}_{3}$ adsorbates. The process was demonstrated using $\mathrm{Si}, \mathrm{SiO}_{2}, \mathrm{SiC}$ and $\mathrm{Si}_{3} \mathrm{~N}_{4}$, and enables high resolution EBIE in the absence of artifacts caused by delocalized spontaneous etching of the substrates. 


\subsection{Acknowledgements}

This work was funded by FEI Company. Aiden Martin is the recipient of a John Stocker Postgraduate Scholarship from the Science and Industry Endowment Fund.

\section{$0.2 \quad$ Associated Content}

\section{Supporting Information}

S1: Notes; S2: Modeling introduction; S3: Temperature dependence of electron beam induced etching; S4: Arrhenius analysis of single step EBIE reactions; S5: Arrhenius analysis of multi-step EBIE reactions; S6: Model input parameters. This material is available free of charge via the Internet at http://pubs.acs. org/. 


\section{References}

(1) Utke, I.; Moshkalev, S.; Russell, P. Nanofabrication Using Focused Ion and Electron Beams: Principles and Applications; Oxford University Press: New York, 2012.

(2) Randolph, S. J.; Fowlkes, J. D.; Rack, P. D. Focused, Nanoscale Electron-Bearn-Induced Deposition and Etching. Crit. Rev. Solid State Mater. Sci. 2006, 31, 55-89.

(3) Toth, M. Advances in Gas-Mediated Electron Beam-Induced Etching and Related Material Processing Techniques. Appl. Phys. A: Mater. Sci. Process. 2014, in press (published online).

(4) Rack, P.; Randolph, S.; Deng, Y.; Fowlkes, J.; Choi, Y.; Joy, D. C. Nanoscale ElectronBeam-Stimulated Processing. Appl. Phys. Lett. 2003, 82, 2326-2328.

(5) Winters, H. F.; Coburn, J. W. Surface Science Aspects of Etching Reactions. Surf. Sci. Rep. 1992, 14, 161-269.

(6) Flamm, D. L. Mechanisms of Silicon Etching in Fluorine-and Chlorine-Containing Plasmas. Pure Appl. Chem. 1990, 62, 1709-1720.

(7) Brannon, J. H. Chemical Etching of Silicon by $\mathrm{CO}_{2}$ Laser-Induced Dissociation of $\mathrm{NF}_{3}$. J. Vac. Sci. Technol., B 1987, 5, 1399-1399.

(8) Bruno, G.; Capezzuto, P.; Cicala, G.; Manodoro, P. Study of the $\mathrm{NF}_{3}$ Plasma Cleaning of Reactors for Amorphous Silicon Deposition. J. Vac. Sci. Technol., A 1994, 12, 690698.

(9) Tasaka, A.; Takahashi, K.; Tanaka, K.; Shimizu, K.; Mori, K.; Tada, S.; Shimizu, W.; Abe, T.; Inaba, M.; Ogumi, Z.; Tojo, T. Plasma Etching of SiC Surface Using NF $3 . J$. Vac. Sci. Technol., A 2002, 20, 1254-1260.

(10) Haaland, P. D.; Jiao, C. Q.; Garscadden, A. Ionization of $\mathrm{NF}_{3}$ by Electron Impact. Chem. Phys. Lett. 2001, 340, 479-483. 
(11) Miotto, R.; Ferraz, A.; Srivastava, G. Dissociative Adsorption of $\mathrm{NF}_{3}$ on $\mathrm{Si}(001)-(2 \times 1)$. Surf. Sci. 2000, 454-456, 152-156.

(12) Junker, K. H.; White, J. Adsorption of $\mathrm{NF}_{3}$ on $\operatorname{Pt}(111)$ : Interactions with Electrons and Photons. Surf. Sci. 1997, 382, 67-78.

(13) Rzeźnicka, I. I.; Lee, J.; Yates, J. T., Jr. Dynamics of $\mathrm{NF}_{3}$ in a Condensed Film on $\mathrm{Au}(111)$ as Studied by Electron-Stimulated Desorption. Surf. Sci. 2006, 600, 44924500.

(14) Walczak, M.; Johnson, A.; Thiel, P.; Madey, T. The Interaction of $\mathrm{NF}_{3}$ with Ru (0001): Order at Steps. J. Vac. Sci. Technol., A 1988, 6, 675-680.

(15) Utke, I.; Hoffmann, P.; Melngailis, J. Gas-Assisted Focused Electron Beam and Ion Beam Processing and Fabrication. J. Vac. Sci. Technol., B 2008, 26, 1197-1276.

(16) Huth, M.; Porrati, F.; Schwalb, C.; Winhold, M.; Sachser, R.; Dukic, M.; Adams, J.; Fantner, G. Focused Electron Beam Induced Deposition: A Perspective. Beilstein J. Nanotechnol. 2012, 3, 597-619.

(17) Lassiter, M. G.; Rack, P. D. Nanoscale Electron Beam Induced Etching: A Continuum Model that Correlates the Etch Profile to the Experimental Parameters. Nanotechnology 2008, 19, 455306.

(18) Smith, D. A.; Fowlkes, J. D.; Rack, P. D. Understanding the Kinetics and Nanoscale Morphology of Electron-Beam-Induced Deposition Via a Three-Dimensional Monte Carlo Simulation: The Effects of the Precursor Molecule and the Deposited Material. Small 2008, 4, 1382-1389.

(19) Fowlkes, J. D.; Rack, P. D. Fundamental Electron-Precursor-Solid Interactions Derived from Time-Dependent Electron-Beam-Induced Deposition Simulations and Experiments. ACS Nano 2010, 4, 1619-1629. 
(20) Randolph, S.; Toth, M.; Cullen, J.; Chandler, C.; Lobo, C. Kinetics of Gas Mediated Electron Beam Induced Etching. Appl. Phys. Lett. 2011, 99, 213103.

(21) Bishop, J.; Lobo, C. J.; Martin, A.; Ford, M.; Phillips, M. R.; Toth, M. The Role of Activated Chemisorption in Electron Beam Induced Deposition. Phys. Rev. Lett. 2012, 109, 146103.

(22) Martin, A.; Phillips, M. R.; Toth, M. Dynamic Surface Site Activation: A Rate Limiting Process in Electron Beam Induced Etching. ACS Appl. Mater. Interfaces 2013, 5, 8002-8007.

(23) Matsui, S.; Mori, K. Direct Writing onto Si by Electron Beam Stimulated Etching. Appl. Phys. Lett. 1987, 51, 1498-1499.

(24) Vanhove, N.; Lievens, P.; Vandervorst, W. Electron Beam Induced Etching of Silicon with $\mathrm{SF}_{6}$. J. Vac. Sci. Technol., B 2010, 28, 1206-1209.

(25) Roediger, P.; Wanzenboeck, H.; Hochleitner, G.; Bertagnolli, E.; Buehler, W. Focused Electron Beam Induced Etching of Silicon by Chlorine Gas: Negative Effects of Residual Gas Contamination on the Etching Process. J. Appl. Phys. 2010, 108, 124316.

(26) Roediger, P.; Hochleitner, G.; Bertagnolli, E.; Wanzenboeck, H.; Buehler, W. Focused Electron Beam Induced Etching of Silicon Using Chlorine. Nanotechnology 2010, 21, 285306.

(27) Danilatos, G. D. Foundations of Environmental Scanning Electron Microscopy. Adv. Electron. Electron Phys. 1988, 71, 109-250.

(28) Thiel, B. L.; Toth, M. Secondary Electron Contrast in Low-Vacuum/Environmental Scanning Electron Microscopy of Dielectrics. J. Appl. Phys. 2005, 97, 051101.

(29) Thiel, B.; Toth, M.; Schroemges, R. P. M.; Scholtz, J. J.; van Veen, G.; Knowles, W. 
Two-Stage Gas Amplifier for Ultrahigh Resolution Low Vacuum Scanning Electron Microscopy. Rev. Sci. Instrum. 2006, 77, 033705-7.

(30) Lobo, C. J.; Martin, A.; Phillips, M. R.; Toth, M. Electron Beam Induced Chemical Dry Etching and Imaging in Gaseous $\mathrm{NH}_{3}$ Environments. Nanotechnology 2012, 23, 375302.

(31) Bresin, M.; Thiel, B. L.; Toth, M.; Dunn, K. A. Focused Electron Beam-Induced Deposition at Cryogenic Temperatures. J. Mater. Res. 2011, 26, 357-364.

(32) Bresin, M.; Toth, M.; Dunn, K. A. Direct-Write 3D Nanolithography at Cryogenic Temperatures. Nanotechnology 2013, 24, 035301.

(33) King, G. M.; Schürmann, G.; Branton, D.; Golovchenko, J. A. Nanometer Patterning with Ice. Nano Lett. 2005, 5, 1157-1160.

(34) Gardener, J. A.; Golovchenko, J. A. Ice-Assisted Electron Beam Lithography of Graphene. Nanotechnology 2012, 23, 185302.

(35) Perentes, A.; Hoffmann, P. Oxygen Assisted Focused Electron Beam Induced Deposition of Si-Containing Materials: Growth Dynamics. J. Vac. Sci. Technol., B 2007, 25, 2233-2238.

(36) Li, J.; Toth, M.; Tileli, V.; Dunn, K. A.; Lobo, C. J.; Thiel, B. L. Evolution of the Nanostructure of Deposits Grown by Electron Beam Induced Deposition. Appl. Phys. Lett. 2008, 93, 023130.

(37) Jansen, H.; Gardeniers, H.; Boer, M. d.; Elwenspoek, M.; Fluitman, J. A Survey on the Reactive Ion Etching of Silicon in Microtechnology. J. Micromech. Microeng. 1999, 6, 14-28.

(38) Vanhove, N.; Lievens, P.; Vandervorst, W. Particle Emission from Chemically Enhanced 
Electron-Beam-Induced Etching of Si: An Approach for Zero-Energy Secondary-Ion Mass Spectrometry. Phys. Rev. B: Condens. Matter Mater. Phys. 2009, 79, 035305.

(39) Vugts, M. J. M. Si $/ \mathrm{XeF}_{2}$ Etching: Temperature Dependence. J. Vac. Sci. Technol., A 1996, 14, 2766-2774.

(40) Hills, M. M. The Interaction of $\mathrm{XeF}_{2}$ with Sapphire. Appl. Surf. Sci. 1994, 78, 165-177.

(41) Kastenmeier, B. E. E.; Matsuo, P. J.; Oehrlein, G. S.; Langan, J. G. Remote Plasma Etching of Silicon Nitride and Silicon Dioxide Using $\mathrm{NF}_{3} / \mathrm{O}_{2}$ Gas Mixtures. J. Vac. Sci. Technol., A 1998, 16, 2047-2056.

(42) Toth, M.; Lobo, C.; Knowles, W.; Phillips, M.; Postek, M.; Vladár, A. Nanostructure Fabrication by Ultra-High-Resolution Environmental Scanning Electron Microscopy. Nano Lett. 2007, 7, 525-530.

(43) Mattausch, H. J. Reactive Ion Etching of Ta-Silicide/Polysilicon Double Layers for the Fabrication of Integrated Circuits. J. Vac. Sci. Technol., B 1983, 1, 15-22. 
Graphical TOC Entry

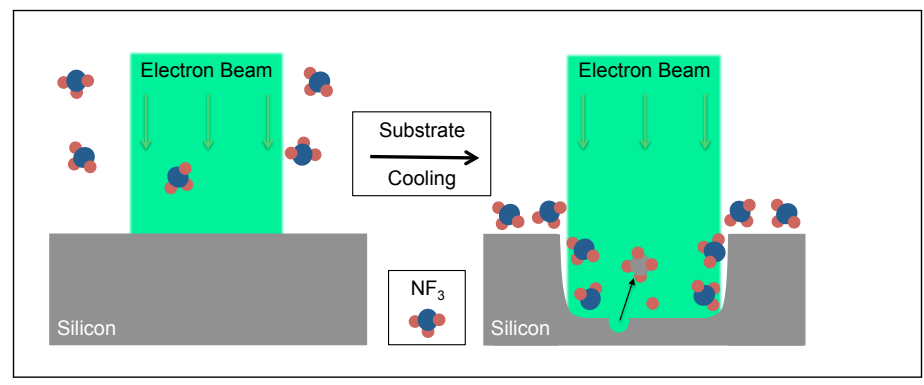

